\title{
Yenilenebilir Enerji Üretim Birimleri İçeren Çevresel-Ekonomik Güç Dağıtımı Probleminin Yüklü Sistem Arama Algoritması ile Çözümü
}

\author{
Serdar Özyön ${ }^{1 *}$ \\ ${ }^{1}$ Kütahya Dumlupınar Üniversitesi, Mühendislik Fakültesi, Elektrik Elektronik Müh. Bölümü, Kütahya, Türkiye (ORCID: 0000-0002-4469-3908)
}

(İlk Geliş Tarihi 2 Ocak 2020 ve Kabul Tarihi 22 Şubat 2020)

(DOI: $10.31590 /$ ejosat.669543)

ATIF/REFERENCE: Ozyon, S. (2020). Yenilenebilir Enerji Üretim Birimleri İçeren Çevresel-Ekonomik Güç Dağıtımı Probleminin Yüklü Sistem Arama Algoritması ile Çözümü. Avrupa Bilim ve Teknoloji Dergisi, (18), 81-90.

$\ddot{O} z$

Elektrik mühendisliği için çözümü büyük bir öneme sahip ve literatürde birçok çalışmada ele alınan çevresel-ekonomik güç dağıtımı problemi, sistem tarafından talep edilen gücü, sistem kısıtları altında en düşük yakıt maliyeti ve emisyon miktarı ile karşılamak olarak tanımlanır. Elektrik enerjisi ihtiyacının karşılanması için genellikle tükenebilir fosil kaynaklı yakıtların kullanılması hem yakıt maliyetini hem de çevreye salınan emisyon miktarlarını ciddi oranda artırmaktadır. Bu maliyet ve emisyon değerlerini azaltmanın diğer bir yolu da elektrik enerjisi üretimi için yakıt maliyeti ve emisyon miktarı sıfır olan yenilenebilir enerji üretim sistemlerinin kullanılmasıdır. Bu sistemlerden en önemli ikisi rüzgâr ve güneş enerjisi üretim sistemleridir. Günümüzde rüzgâr ve güneş enerjisi üretim sistemlerinin kullanımı giderek artsa da bu sistemler birçok uygulamada yerel yükü beslemektedir. Bu çalışmada termik üretim birimleri bulunan bir güç sistemine, rüzgâr ve güneş enerjisi üretim birimleri eklenerek sistemin aynı yük talebi için maliyet, emisyon ve iletim hattı kayıpları hesaplanmıştır. Çalışmada çevresel-ekonomik güç dağıtım probleminin optimizasyonu yüklü sistem arama (CSS) algoritmasıyla yapılmıştır. Örnek sistem olarak belirlenen IEEE 30-bara 6-generatörlü güç sistemi, CSS algoritması ile iki kez çözülmüştür. İlk çözümde sistemdeki güç talebi sadece termik üretim birimleri tarafından karş1lanırken, ikinci çözümde ise sistemdeki iki yük barasına, o baralardaki yükü besleyecek rüzgâr ve güneş enerjisi üretim birimi eklenmiştir. Problemin çözümünde birbirinden farklı birimdeki hem yakıt maliyeti hem de emisyon miktarının aynı anda minimizasyonu yer aldığından, bu iki amaç ağırlıklı toplam metodu ile tek bir amaç fonksiyonunda birleştirilmiştir. Örnek güç sisteminin iletim hattı kayıpları B-kayıp matrisleri kullanılarak yaklaşık hesaplanmıştır. Her iki çözüm içinde bulunan maliyet değerleri, emisyon miktarları ve iletim hattı kayıpları karşılaştırılmış ve sonuçlar tartışılmıştır.

\section{The Solution of Environmental-Economic Power Dispatch Problem Including Renewable Power Generation Units with Charged System Search Algorithm}

\begin{abstract}
Environmental-economic power dispatch problem the solution of which has a great importance for electrical engineering and which is handled in many studies in literature, is defined as the meeting of the demanded power by the system, with the lowest fuel cost and emission amount under the system constraints. The use of exhaustible fossil-based fuels in order to meet the electrical power need
\end{abstract}

\footnotetext{
* Sorumlu Yazar: Kütahya Dumlupınar Üniversitesi, Mühendislik Fakültesi, Elektrik Elektronik Mühendisliği Bölümü, Kütahya, Türkiye. ORCID: 0000-0002-4469-3908, serdar.ozyon@dpu.edu.tr
} 
increases both the fuel cost and the emission amount spread to the environment seriously. Another way to decrease these cost and emission values is the use of renewable power generation systems for power generation, the fuel cost and the emission amount of which is zero. The most important two of these systems are wind and solar power generation systems. Today, although the use of wind and solar power generation systems increases, these systems feed the local load in many applications. In this study, by adding wind and solar power generation units to a power system having thermal generation units, the cost, emission and transmission line losses of the system for the same load demand have been calculated. In the study, the optimization of environmental-economic power dispatch problem has been done with charged system search (CSS) algorithm. IEEE 30-bus 6-generator power system, which was defined as the sample system, has been solved with CSS algorithm twice. While the power need in the system has been only met by the thermal generation units in the first solution, in the second solution, wind and solar power generation unit has been added to the two load buses feeding the load in these buses. In the solution of the problem since the minimization of both the fuel cost and the emission amount in different units from each other, takes place at the same time, these two aims have been united in one purpose function with weighted sum method. The transmission line losses of the sample system have been calculated approximately by using B-loss matrices. The cost values, emission amounts and transmission line losses found for both solutions have been compared and the results have been discussed.

Keywords: Environmental-economic power dispatch, Renewable power generation systems, Fuel cost, Emission amount, Charged system search (CSS) algorithm.

\section{Giriş}

Elektrik mühendisliği alanında çözülmesi gereken önemli problemlerden biri de çevresel-ekonomik güç dağıtımı problemidir. Ekonomik güç dağıtımı, sistem kısıtları altında minimum maliyetle talep edilen gücün üretim birimleri tarafından karşılanması olarak tanımlanır. Termik üretim birimleri tarafından çevreye salınan zararlı gazların minimizasyonu da probleme eklendiğin de ise problem çevresel-ekonomik güç dağıtımı olarak isimlendirilir. Tanımlanan problem çok amaçlı, kısıtlı ve karmaşık yapıdadır. Bu tür problemlerin nümerik yöntemlerle çözümü zor ya da uzun süreler almaktadır. Çevresel-ekonomik güç dağıtımının ana fikri, yakıt maliyeti daha ucuz ve emisyon salınımı daha olan üretim birimlerini, enerji üretiminde daha fazla kullanmaktır [Özyön ve ark. 2015; Basu, 2015].

Son yıllarda bu tür problemlerin çözümünde sıklıkla sezgisel algoritmalar kullanılmaktadır. Farklı yapıda ve değişik kısıtlar altında çevresel/ekonomik güç dağıtımı problemleri literatürde birçok optimizasyon algoritması ile çözülmüştür. Bunlardan bazıları genetik algoritma [Özyön ve ark. 2015], evrimsel algoritma [Zhu ve ark. 2014], nokta kestirim metodu [Abarghooee ve ark. 2012], hibrid çiçek tozlaşma algoritması [Dubey ve ark. 2015], parçacık sürü optimizasyonu [Jiang ve ark. 2015], yapay arı koloni algoritması [Jadhay ve Roy, 2013], güve sürüsü algoritması [Jevtic ve ark. 2017] ve diferansiyel gelişim algoritması [Bhattacharya ve Chattopadhyay, 2011] olarak siralanabilir.

Güç üretiminde termik yakıt kullanan üretim birimlerinin artması hem yakıt maliyetlerini hem de emisyon miktarlarını artırmaktadır. Bu değerlerin azaltılması için güç sistemlerinde yenilenebilir enerji üretim sistemlerinin (YEÜS) kullanımı da giderek yaygınlaşmaktadır. YEÜS'ler yakıt maliyetleri ve emisyonları olmayan enerji üretim birimleridir. Yaygın olarak kullanılan ve teknolojik olarak gelişimleri hızla ilerleyen rüzgâr enerji santralleri ve güneş enerji santralleri başlıca yenilenebilir enerji üretim sistemleri olarak sayılabilir.

Yapılan çalışmada termik üretim birimleri bulunan bir güç sistemine, rüzgâr ve güneş enerjisi üretim birimleri eklenerek sistemin aynı yük talebi için maliyet, emisyon ve iletim hattı kayıpları hesaplanmıştır. Çalışmada çevresel-ekonomik güç dağıtım probleminin optimizasyonu yüklü sistem arama (CSS) algoritmasıyla yapılmıştır. Örnek sistem olarak belirlenen IEEE 30-bara 6-generatörlü güç sistemi, CSS algoritması ile iki kez çözülmüştür. İlk çözümde sistemdeki güç talebi sadece termik üretim birimleri tarafından karşılanırken, ikinci çözümde ise sistemdeki iki yük barasına, o baralardaki yükü besleyecek rüzgâr ve güneş enerjisi üretim birimi eklenmiştir. Problemin çözümünde birbirinden farklı birimdeki hem yakıt maliyeti hem de emisyon miktarının aynı anda minimizasyonu yer aldığından, bu iki amaç ağırlıklı toplam metodu ile tek bir amaç fonksiyonunda birleştirilmiştir. Örnek güç sisteminin iletim hattı kayıpları B-kayıp matrisleri kullanılarak yaklaşık hesaplanmıştır. Her iki çözüm içinde bulunan maliyet değerleri, emisyon miktarları ve iletim hattı kayıpları karşılaştırılmış ve sonuçlar tartışılmıştır.

\section{Yüklü Sistem Arama Algoritmasi (CSS)}

Yüklü sistem arama adı verilen yeni bir meta-sezgisel algoritma türü Kaveh ve Talatahari tarafından ortaya konulmuştur. Yüklü sistem arama (CSS) algoritmasının temeli Newton hareket kanunları ve elektrik fiziğinden Coulomb ve Gauss kanunlarına dayalıdır. $\mathrm{Bu}$ algoritmada her ajan yüklü bir parçacıktır (CP). Her CP, Coulomb ve Gauss kanunlarına göre diğer yüklü parçacıklar üzerine elektrik gücü uygulayan yüklü bir küre olarak düşünülür. Sonuç olarak ortaya çıkan güçler ve hareket kanunları yüklü parçacıkların (CPs) yeni konumlarını belirler. Birinci iterasyondaki yüklü parçacıkların yeni konumları rastgele belirlenir ve sonraki iterasyonlar için yeni konum ve hız vektörleri aşağıdaki gibi elde edilir [Kaveh ve Talatahari, 2010; Özyön ve ark. 2012; Tabrizian ve ark. 2014].

$$
\begin{gathered}
X_{j, y e n i}=\operatorname{rand}_{j, 1} \cdot k_{a} \cdot \frac{F_{j}}{m_{j}} \cdot \Delta t^{2}+\operatorname{rand}_{j, 2} \cdot k_{v} \cdot V_{j, e s k i} \cdot \Delta t+X_{j, e s k i} \\
V_{j, y e n i}=\frac{X_{j, y e n i}-X_{j, e s k i}}{\Delta t}
\end{gathered}
$$


Burada $k_{a}$ ve $k_{v}$ sırasıyla ivme ve hız katsayıları, $\operatorname{rand}_{j, 1}$ ve $\operatorname{rand}_{j, 2}(0,1)$, aralığında uniform yayılmış iki rastgele sayıdır. $j$. CP için ortaya çıkan güç vektörleri $F_{j}$, aşağıdaki gibi hesaplanır.

$$
F_{j}=q_{j} \sum_{i, i \neq j}\left(\frac{q_{i}}{a^{3}} r_{i j} i_{1}+\frac{q_{i}}{r_{i j}^{2}} i_{2}\right) p_{i j}\left(X_{i}-X_{j}\right) \quad\left(\begin{array}{l}
j=1,2, \ldots, N \\
i_{1}=1, i_{2}=0 \Leftrightarrow r_{i j}<a \\
i_{1}=0, i_{2}=1 \Leftrightarrow r_{i j}>a
\end{array}\right.
$$

Burada her bir CP için yükün büyüklüğü $q_{i}$, ve $a$ değeri aşağıdaki şekilde tanımlanır.

$$
\begin{gathered}
q_{i}=\frac{\text { fit }(i)-\text { fitworst }}{\text { fitbest }- \text { fitworst }}, \quad i=1,2, \ldots, N \\
a=0,10 x \max \left(\left\{x_{i, \max }-x_{i, \min } \mid i=1,2, \ldots, n\right\}\right)
\end{gathered}
$$

Burada fitbest ve fitworst bütün CP'lerin en iyi ve en kötü uygunluğudur. fit (i) ajan $i$ 'nin uygunluğu, ve $N$ ise yüklü parçacıkların toplam sayısıdır. İki CP arasındaki ayrılma mesafesi $r_{i j}$, aşağıdaki şekilde hesaplanır.

$$
r_{i j}=\frac{\left\|X_{i}-X_{j}\right\|}{\left\|\left(X_{i}-X_{j}\right) / 2-X_{\text {eniyi }}\right\|+\varepsilon}
$$

Burada $X_{i}$ ve $X_{j}, i$. ve $j$. CPlerin konumlarıdır, $X_{\text {eniyi }}$ en iyi şimdiki CP'nin konumudur ve $\varepsilon$ küçük pozitif bir rakamdır. Her bir CP'yi diğer CP'lere doğru hareket ettirme olasılığı aşağıdaki denklemi kullanarak belirlenir.

$$
p_{i j}= \begin{cases}1, & \frac{\text { fit }(i)-\text { fitbest }}{\text { fit }(j)-\text { fit }(i)}>\text { rand } \vee f i t(j)>f i t(i) \\ 0, & \text { değilse }\end{cases}
$$

CP'lerin yeni konumlarının belirlenmesinden sonra, çözüm vektörünün herhangi bir parçası izin verilen sınırlardan saparsa, elle düzeltme yaklaşımı kullanılarak düzeltilir. Yüklü hafıza (CM) son iterasyona kadar bir dizi en iyi çözümü saklamak için kullanılır. Daha iyi yeni çözümler $C M$ 'ye dahil edilir ve en kötüler $C M$ 'den çıkarılır. CSS algoritmasının akış diyagramı Şekil 1'de verilmiştir [Kaveh ve Talatahari, 2010; Özyön ve ark. 2012; Tabrizian ve ark. 2014].

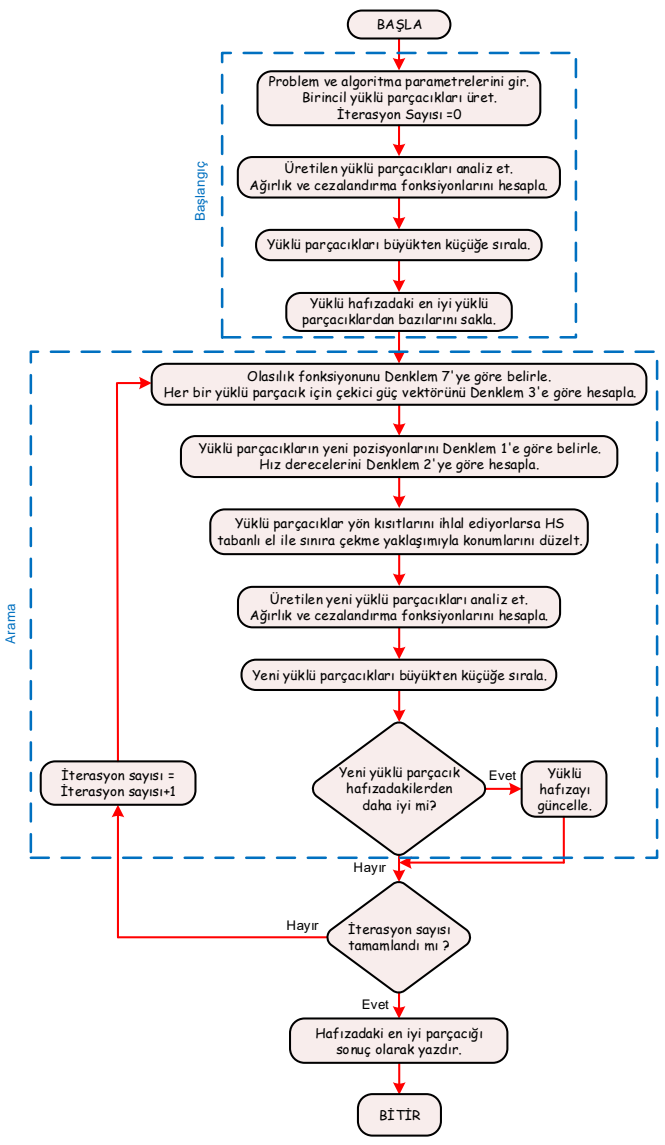

Şekil 1. CSS algoritmasının akış diyagramı 


\section{3. Çevresel-Ekonomik Güç Dağıtımı}

Sistemin kısıtları altında, ağırlıklı toplam metoduyla $(A T M)$ birleştirilmiş amaç fonksiyonunun (toplam termik yakıt maliyeti ve toplam $N O_{x}$ emisyon miktarı) minimize edilmesi çevresel-ekonomik güç dağıtımı probleminin çözümü olarak tanımlanır. Üretim birimlerine ait konveks yakıt maliyet fonksiyonu denklem (8)'de verilmiştir [Jevtis ve ark. 2017; Özyön ve ark. 2012].

$$
F_{i}\left(P_{i}\right)=a_{i}+b_{i} P_{i}+c_{i} P_{i}^{2}, \quad(\$ / h)
$$

Denklemde $F_{i}\left(P_{i}\right), i$. üretim biriminin yakıt maliyet fonksiyonunu, $a_{i}, b_{i}$ ve $c_{i} i$. üretim biriminin maliyet fonksiyonu katsayılarını, $P_{i}$ ise $i$. üretim biriminin çıkış gücünü göstermektedir ve birimi $M W$ olarak alınmaktadır. Her bir termik üretim birimi tarafından çevreye salınan $N O_{x}$ emisyon miktarı, üretim birimi tarafından üretilen aktif güç cinsinden denklem (9)'da tanımlanmıştır.

$$
E_{i}\left(P_{i}\right)=d_{i}+e_{i} P_{i}+f_{i} P_{i}^{2}+g_{i} \exp \left(h_{i} P_{i}\right),(\text { ton } / h)
$$

Denklemde yer alan $E_{i}\left(P_{i}\right), i$. üretim biriminin $N O_{x}$ emisyon miktarı fonksiyonunu, $d_{i}, e_{i}, f_{i}, g_{i}$ ve $h_{i} i$. üretim biriminin emisyon fonksiyonu katsayılarını göstermektedir. Kayıplı bir güç sistemindeki, güç eşitlik kısıtı denklem (3)'de verilmiştir.

$$
\sum_{i \in N_{G}} P_{i}-P_{\text {yük }}-P_{\text {kayp }}=0
$$

Denklemde $P_{\text {yük }}$ sistemin talep ettiği yük miktarını, $P_{\text {kayıp }}$ ise iletim hattı kayıplarını göstermektedir. Termik üretim birimlerinin çalışma sınır değerleri denklem (11)'de gösterilmiştir.

$$
P_{i}^{\min } \leq P_{i} \leq P_{i}^{\max },\left(i \in N_{G}\right)
$$

Denklemde $N_{G}$ sistemdeki tüm termik üretim birimlerin kümesini temsil etmektedir. Sistemin iletim hatlarında meydana gelen güç kayıpları $\left(P_{\text {kayp }}\right)$, yaklaşık olarak $B$ kayıp matrisleri kullanılarak denklem (12) ile hesaplanmıştır.

$$
P_{k a y p p}=\sum_{i \in N_{G}} \sum_{j \in N_{G}} P_{i} B_{i j} P_{j}+\sum_{i \in N_{G}} B_{0 i} P_{i}+B_{00}
$$

Çevresel-ekonomik güç dağıtım probleminde birbirinden bağımsız iki amaç vardır. Bu amaçlar ATM ile birleştirilmiş ve minimize edilecek amaç fonksiyonu $A F$, denklem (13)'de verilmiştir [Jevtis ve ark. 2017; Özyön ve ark. 2012].

$$
A F=w \sum_{i \in N_{G}} F_{i}\left(P_{i}\right)+(1-w) \gamma \sum_{i \in N_{G}} E_{i}\left(P_{i}\right)
$$

Denklemde $\gamma$, iki amaç arasındaki dengeyi sağlamak için kullanılan ölçekleme faktörünü, $w$ ise $0 \leq w \leq 1$ aralığında 0,1 aralıkla değişen ağırlık faktörünü göstermektedir. Burada $w=1,0$ değeri sadece termik yakıt maliyetinin, $w=0,0$ değeri ise sadece $N O_{x}$ emisyon miktarının minimize edilmesine karşılık gelmektedir. Sistemdeki toplam termik yakıt maliyeti $F_{T}\left(P_{i}\right)$ ve toplam $N O_{x}$ emisyon miktarı $E_{T}\left(P_{i}\right)$ sırasıyla denklem (14) ve (15) kullanılarak hesaplanmıştır.

$$
\begin{gathered}
F_{T}\left(P_{i}\right)=\sum_{i \in N_{G}} F_{i}\left(P_{i}\right), \quad(\$ / \mathrm{h}) \\
E_{T}\left(P_{i}\right)=\sum_{i \in N_{G}} E_{i}\left(P_{i}\right), \quad(\text { ton } / h)
\end{gathered}
$$

\section{4. Örnek Güç Sistemi ve Çözümü}

CSS algoritması IEEE 30-baralı 6-generatörlü çevresel-ekonomik güç dağıtım problemine 2,834 pu yük talebi için iletim hattı kayıpları dikkate alınarak iki farklı durumda uygulanmıştır. İlk durumda Tablo 1'de verilen sistemdeki yük talebi sadece termik üretim birimleri tarafından karşılanmıştır. İkinci durumda ise 14. baradaki 0,062 pu'luk yük yerel bir rüzgar enerji santrali tarafından ve 11. baradaki 0,032 pu'luk yük talebi ise yerel bir güneş enerji santrali tarafından karşılandığı varsayılarak sistem tekrar çözülmüştür. Bu baraların seçilme nedenleri, bu baralar tarafından talep edilen güç miktarının, bir rüzgar enerji santrali tarafından karşılanabilecek olmasıdır. Her iki durum içinde algoritma $30 \mathrm{kez}$ koşturulmuştur. Test sisteminde 41 adet iletim hattı ve 21 adet yük barası bulunmaktadır. Test sisteminde bir 1 nolu generatörün bağlı olduğu bara salınım barası ve baz değerler ise $S_{b a z}=100 M V A$, $V_{b a z}=230 \mathrm{kV}$ ve $Z_{b a z}=529 \mathrm{Ohm}$ olarak alınmıştır. Sistemin tek hat diyagramı Şekil 3'de verilmiştir. Yapılan çalışmada CSS parametreleri, iterasyon sayısı 300 , popülasyon büyüklüğü $40, k v_{i l k} 0,5, k v_{\text {son }} 0, k a_{i l k} 0,5, k a_{\text {son }} 0$ ve $r 0,01$ olarak alınmıştır. Çalışmada ölçekleme faktörü $\gamma=1000$ olarak alınmıştır. CSS algoritması, ekonomik dağıtım probleminin çözümü için Intel Xeon E5-2637 v4 $3.50 \mathrm{GHz}$ işlemcili ve $128 \mathrm{~GB}$ RAM bellekli iş istasyonunda çalıştırılmıştır. Test sistemindeki termik üretim birimlerine ait maliyet 
European Journal of Science and Technology

fonksiyonu katsayıları ve bu birimlerin aktif güç üretim sınırları Tablo 2'de, iletim hatlarında meydana gelen aktif güç kayıplarının hesaplanmasında kullanılan $B$-kayıp matrisi değerleri ise Tablo 3'de verilmiştir [Jevtis ve ark. 2017; Özyön ve ark. 2012].

Tablo 1. Örnek sistemdeki yük değerleri

\begin{tabular}{cccccc}
\hline Bara $\boldsymbol{N o}$ & $\boldsymbol{P}(\boldsymbol{p u})$ & $\boldsymbol{Q}(\boldsymbol{p u})$ & Bara $\boldsymbol{N o}$ & $\boldsymbol{P}(\boldsymbol{p u})$ & $\boldsymbol{Q}(\boldsymbol{p u})$ \\
\hline 1 & 0 & 0 & 16 & 0,035 & 0,018 \\
2 & 0,217 & 0,127 & 17 & 0,090 & 0,058 \\
3 & 0,024 & 0,012 & 18 & 0,032 & 0,009 \\
4 & 0,076 & 0,016 & 19 & 0,095 & 0,034 \\
5 & 0,942 & 0,190 & 20 & 0,022 & 0,007 \\
6 & 0 & 0 & 21 & 0,175 & 0,112 \\
7 & 0,228 & 0,109 & 22 & 0 & 0 \\
8 & 0,3 & 0,300 & 23 & 0,032 & 0,016 \\
9 & 0 & 0 & 24 & 0,087 & 0,067 \\
10 & 0,058 & 0,020 & 25 & 0 & 0 \\
11 & 0 & 0 & 26 & 0,035 & 0,023 \\
12 & 0,112 & 0,075 & 27 & 0 & 0 \\
13 & 0 & 0 & 28 & 0 & 0 \\
14 & 0,062 & 0,016 & 29 & 0,024 & 0,009 \\
15 & 0,082 & 0,025 & 30 & 0,106 & 0,019 \\
\hline
\end{tabular}

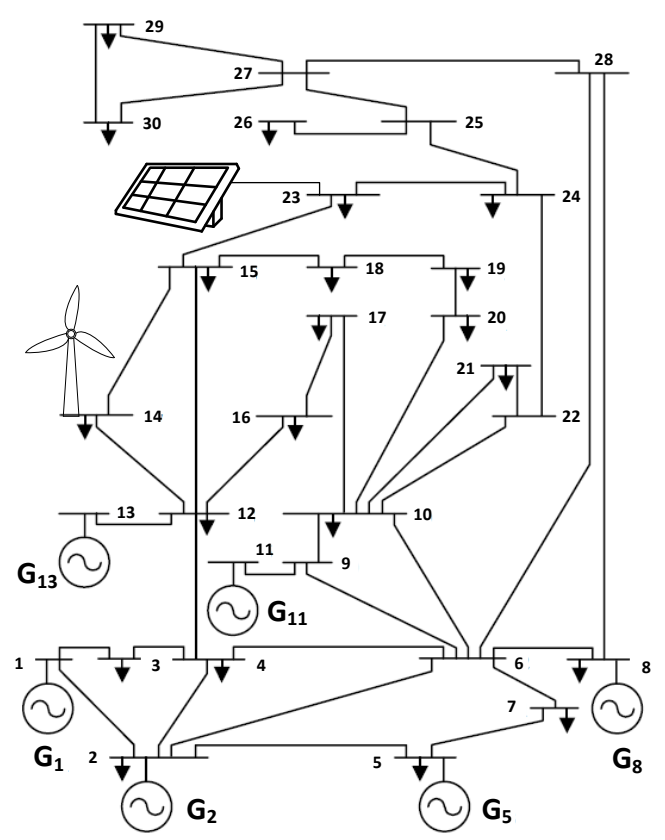

Şekil 2. Örnek sisteme ait tek hat diyagramı

Tablo 2. Örnek sistemlere ait üretim birimlerinin maliyet katsayıları ve aktif güç üretim sinırları

\begin{tabular}{ccccccc}
\hline Bara $\boldsymbol{N o}$ & $\mathbf{1}$ & $\mathbf{2}$ & $\mathbf{5}$ & $\boldsymbol{8}$ & $\mathbf{1 1}$ & $\mathbf{1 3}$ \\
\hline$a$ & 10 & 10 & 20 & 10 & 20 & 10 \\
$b$ & 200 & 150 & 180 & 100 & 180 & 150 \\
$c$ & 100 & 120 & 40 & 60 & 40 & 100 \\
$d$ & $4,091 \mathrm{e}-2$ & $2,543 \mathrm{e}-2$ & $4,258 \mathrm{e}-2$ & $5,326 \mathrm{e}-2$ & $4,258 \mathrm{e}-2$ & $6,131 \mathrm{e}-2$ \\
$e$ & $-5,554 \mathrm{e}-2$ & $-6,047 \mathrm{e}-2$ & $-5,094 \mathrm{e}-2$ & $-3,550 \mathrm{e}-2$ & $-5,094 \mathrm{e}-2$ & $-5,555 \mathrm{e}-2$ \\
$f$ & $6,49 \mathrm{e}-2$ & $5,638 \mathrm{e}-2$ & $4,586 \mathrm{e}-2$ & $3,38 \mathrm{e}-2$ & $4,586 \mathrm{e}-2$ & $5,151 \mathrm{e}-2$ \\
$g$ & $2,0 \mathrm{E}-4$ & $5,0 \mathrm{E}-4$ & $1,0 \mathrm{E}-6$ & $2,0 \mathrm{E}-3$ & $1,0 \mathrm{E}-6$ & $1,0 \mathrm{E}-5$ \\
$h$ & 2,857 & 3,333 & 8,0 & 2,0 & 8,0 & 6,667 \\
$P_{\min }(p u)$ & 0,05 & 0,05 & 0,05 & 0,05 & 0,05 & 0,05 \\
$P_{\max }(p u)$ & 1,50 & 1,50 & 1,50 & 1,50 & 1,50 & 1,50 \\
\hline
\end{tabular}


Avrupa Bilim ve Teknoloji Dergisi

Tablo 3. Örnek sistemlere ait B-kaylp matrisi değerleri

\begin{tabular}{c}
{$[B]=\left[\begin{array}{cccccc}0,1382 & -0,0299 & 0,0044 & -0,0022 & -0,0010 & -0,0008 \\
-0,0299 & 0,0487 & -0,0025 & 0,0004 & 0,0016 & 0,0041 \\
0,0044 & -0,0025 & 0,0182 & -0,0070 & -0,0066 & -0,0066 \\
-0,0022 & 0,0004 & -0,0070 & 0,0137 & 0,0050 & 0,0033 \\
-0,0010 & 0,0016 & -0,0066 & 0,0050 & 0,0109 & 0,0005 \\
-0,0008 & 0,0041 & -0,0066 & 0,0033 & 0,0005 & 0,0244\end{array}\right]$} \\
{$\left[B_{0}\right]=\left[\begin{array}{cccccc}-0,0107 & 0,0060 & -0,0017 & 0,0009 & 0,0002 & 0,0030\end{array}\right]$} \\
$B_{00}=0,00098573$ \\
\hline
\end{tabular}

Birinci ve ikinci durumda test sistemi, farklı ağırlık değerleri için CSS ile 30'ar kez çözülmüştür. Çözümlerden elde edilen istatistiki değerleri Tablo 4'te ve bu çözümlerden eniyi yakıt maliyeti değerine sahip çözümlere ait üretilen toplam güçler, toplam yakıt maliyetleri, toplam $N O_{x}$ emisyon miktarları ve iletim hattı kayıpları ise YEÜS'süz durum için Tablo 5 'te, YEÜS'lü durum için Tablo 6'da verilmiştir.

Tablo 4. CSS ile 30 çözüm için elde edilen veriler

\begin{tabular}{|c|c|c|c|}
\hline & & YEÜS'süz & YË̈S'lü \\
\hline \multirow{5}{*}{$w=1,0$} & En kötü $F(\$ / h)$ & 605,998369 & 584,923977 \\
\hline & Ortalama $F(\$ / h)$ & 605,998369 & 584,923971 \\
\hline & En İyi $F(\$ / h)$ & 605,998369 & 584,923971 \\
\hline & St. Sapma & 0,000000 & 0,000001 \\
\hline & Süre $(s)$ & 6,97118 & 6,94812 \\
\hline \multirow{5}{*}{$w=0,0$} & En kötü $E($ ton $/ h)$ & 0,194178 & 0,194297 \\
\hline & Ortalama $E(t o n / h)$ & 0,194178 & 0,194297 \\
\hline & En İyi $E(t o n / h)$ & 0,194178 & 0,194297 \\
\hline & St. Sapma & 0,000000 & 0,000000 \\
\hline & Süre $(s)$ & 7,71113 & 7,53539 \\
\hline
\end{tabular}

Tablo 5. CSS ile elde edilen eniyi çözümlere ait sonuçlar (YEÜS'süz)

\begin{tabular}{|c|c|c|c|}
\hline \multirow{3}{*}{ YEÜS'süz } & $w=1,0$ & $\begin{array}{c}P_{\text {üretilen }}(p u) \\
F_{T}(\$ / h) \\
E_{T}(\text { ton } / h) \\
P_{\text {kayıp }}(p u) \\
\end{array}$ & $\begin{array}{c}2,859562 \\
605,998369 \\
0,220729 \\
0,025562 \\
\end{array}$ \\
\hline & $w=0,5$ & $\begin{array}{c}P_{\text {üretilen }}(p u) \\
F_{T}(\$ / h) \\
E_{T}(\text { ton } / h) \\
P_{\text {kayıp }}(p u)\end{array}$ & $\begin{array}{c}2.859327 \\
612.252793 \\
0.203570 \\
0.025327\end{array}$ \\
\hline & $w=0,0$ & $\begin{array}{c}P_{\text {üretilen }}(p u) \\
F_{T}(\$ / h) \\
E_{T}(\text { ton } / h) \\
P_{\text {kayıp }}(p u) \\
\end{array}$ & $\begin{array}{c}2,869330 \\
646,207000 \\
0,194179 \\
0,035330 \\
\end{array}$ \\
\hline \multirow{3}{*}{ YEÜS'lü } & $w=1,0$ & $\begin{array}{c}P_{\text {üretilen }}(p u) \\
F_{T}(\$ / h) \\
E_{T}(\text { ton } / h) \\
P_{\text {kaylp }}(p u) \\
\end{array}$ & $\begin{array}{c}2,764417 \\
584,923971 \\
0,220501 \\
0,024417 \\
\end{array}$ \\
\hline & $w=0,5$ & $\begin{array}{c}P_{\text {üretilen }}(p u) \\
F_{T}(\$ / h) \\
E_{T}(\text { ton } / h) \\
P_{\text {kaylp }}(p u) \\
\end{array}$ & $\begin{array}{c}2.763869 \\
591.091415 \\
0.203600 \\
0.023869 \\
\end{array}$ \\
\hline & $w=0,0$ & $\begin{array}{c}P_{\text {üretilen }}(p u) \\
F_{T}(\$ / h) \\
E_{T}(\text { ton } / h) \\
P_{\text {kaylp }}(p u) \\
\end{array}$ & $\begin{array}{c}2,773254 \\
624,801621 \\
0,194297 \\
0,033254 \\
\end{array}$ \\
\hline
\end{tabular}


CSS algoritması, birinci ve ikinci durum için sadece yakıt maliyeti göz önüne alınarak $(w=1,0)$ örnek güç sistemine uygulandığında elde edilen sırasıyla toplam yakıt maliyetinin iterasyon sayılarına göre değişimleri Şekil 3 'te, toplam $N O_{x}$ emisyon miktarının iterasyon sayılarına göre değişimleri Şekil 4'te, sistemde üretilen güçlerin iterasyon sayılarına göre değişimleri Şekil 5'de, iletim hattı kayıplarının iterasyon sayılarına göre değişimleri Şekil 6'de ve kutu grafikleri ise Şekil 7'de verilmiştir.
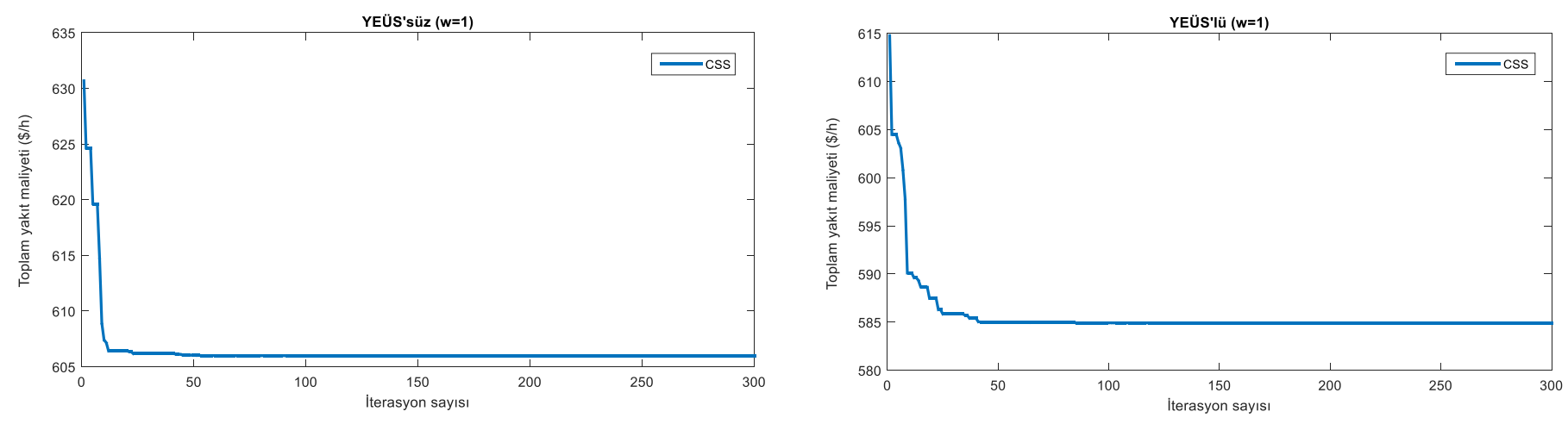

Şekil 3. İterasyon sayısına göre toplam yakıt maliyetlerindeki değişimler
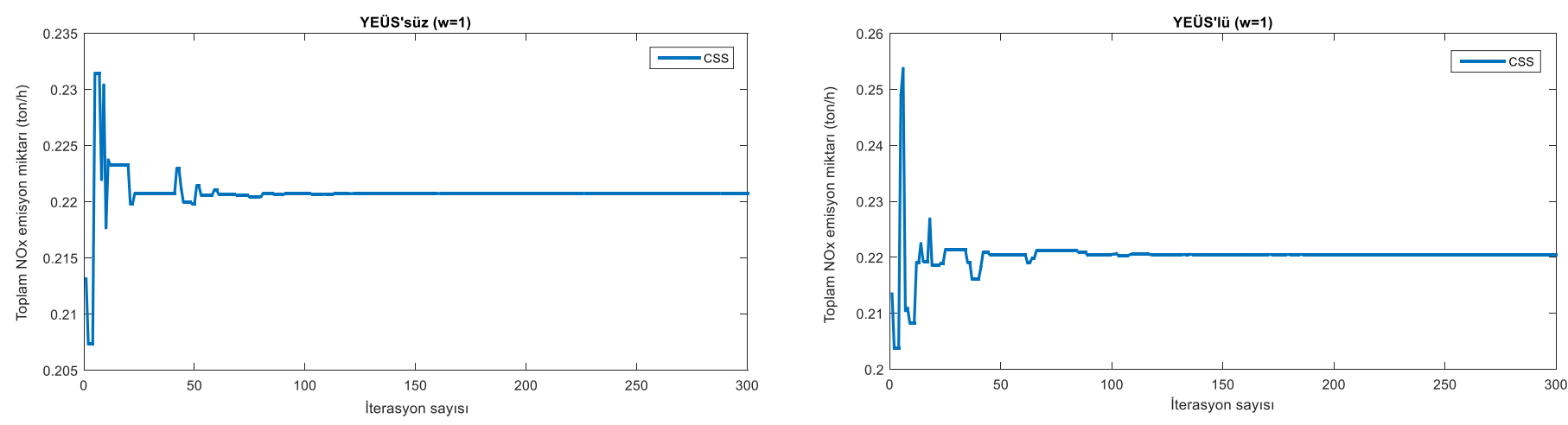

Şekil 4. İterasyon sayısına göre toplam $N O_{x}$ emisyon miktarlarındaki değişimler
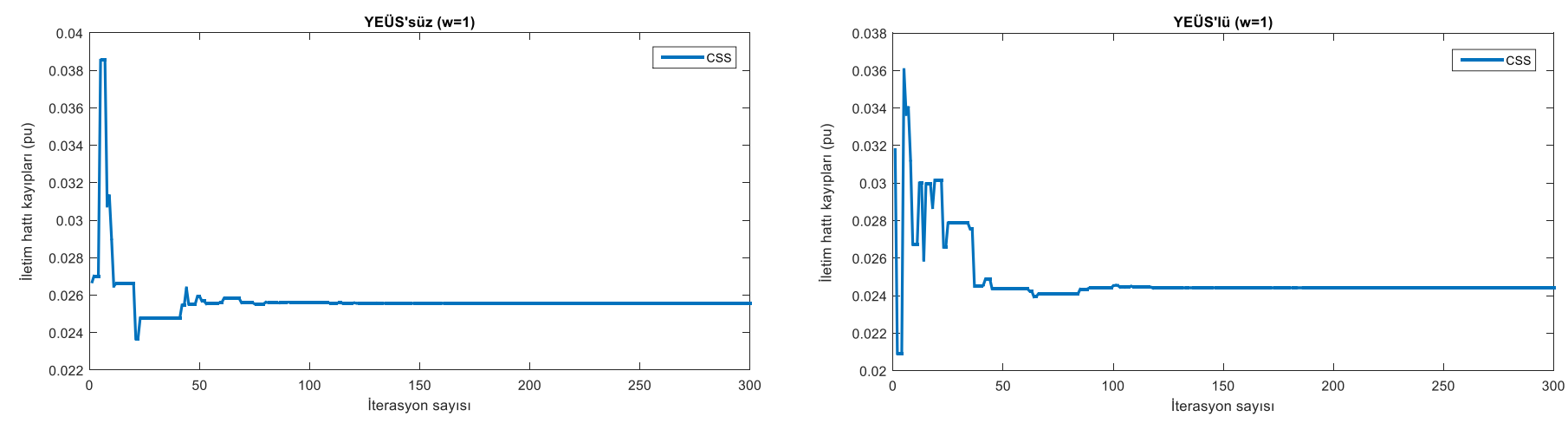

Şekil 5. İterasyon sayısına göre iletim hattı kayıplarındaki değişimler
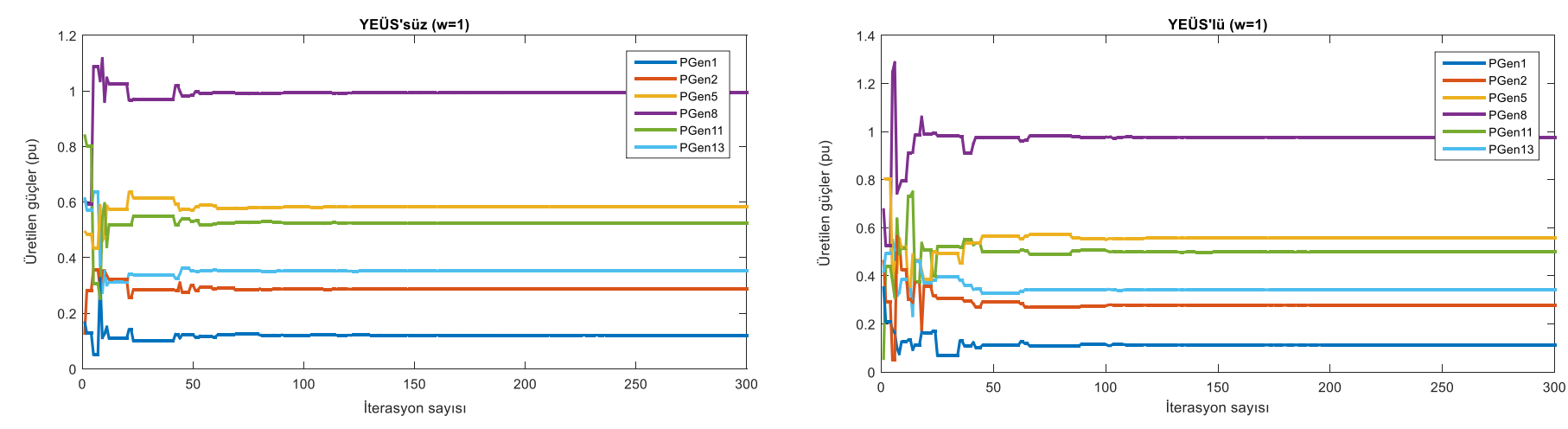

Şekil 6. İterasyon sayısına göre üretilen aktif güçlerdeki değişimler 

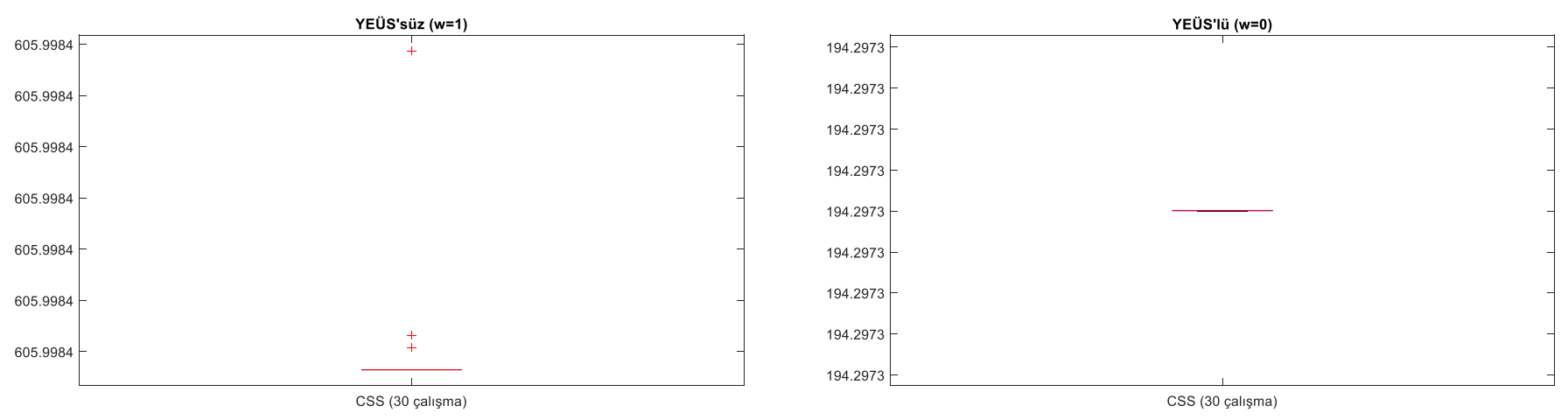

Şekil 7. 30’ar çözüme ait kutu grafikleri

Şekil 3'e bakıldığında yakıt maliyetindeki değişimlerin hem YEÜS'süz hem de YEÜS'lü durum için yaklaşık 45. iterasyonda en iyi değerlerine yakınsadığ 1 görülmektedir. YEÜS'süz durumda toplam yakıt maliyeti değeri $w=1,0$ için $605,998369 \$ / h$ olarak elde edilmiştir. YEÜS'lü durumda ise toplam yakıt maliyeti değeri $w=1,0$ için 584,923971 $\$ / h$ olarak elde edilmiştir ve iki durum arasında $w=1,0$ için yaklaşık $21 \$ / h$ 'lik, ekonomik fayda sağlanmıştır. İletim hattı kayıplarına bakıldığında da YEÜS'lü sistemin iletim hattı kayıpları daha azdır. Kutu grafiklerine bakıldığında ise YEÜS'lü durumda daha kararlı bir arama yapılmıştır, YEÜS'süz durumda 30 çalışmada üç adet sapan değer mevcuttur.

CSS algoritması, birinci ve ikinci durum için sadece toplam $N O_{x}$ emisyon miktarı göz önüne alınarak $(w=0,0)$ örnek güç sistemine uygulandığında elde edilen sırasıyla toplam yakıt maliyetinin iterasyon sayılarına göre değişimleri Şekil 8'de, toplam $N O_{x}$ emisyon miktarının iterasyon sayılarına göre değişimleri Şekil 9'da, sistemde üretilen güçlerin iterasyon sayılarına göre değ işimleri Şekil 10'da, iletim hattı kayıplarının iterasyon sayılarına göre değişimleri Şekil 11'de ve kutu grafikleri ise Şekil 12'de verilmiştir.
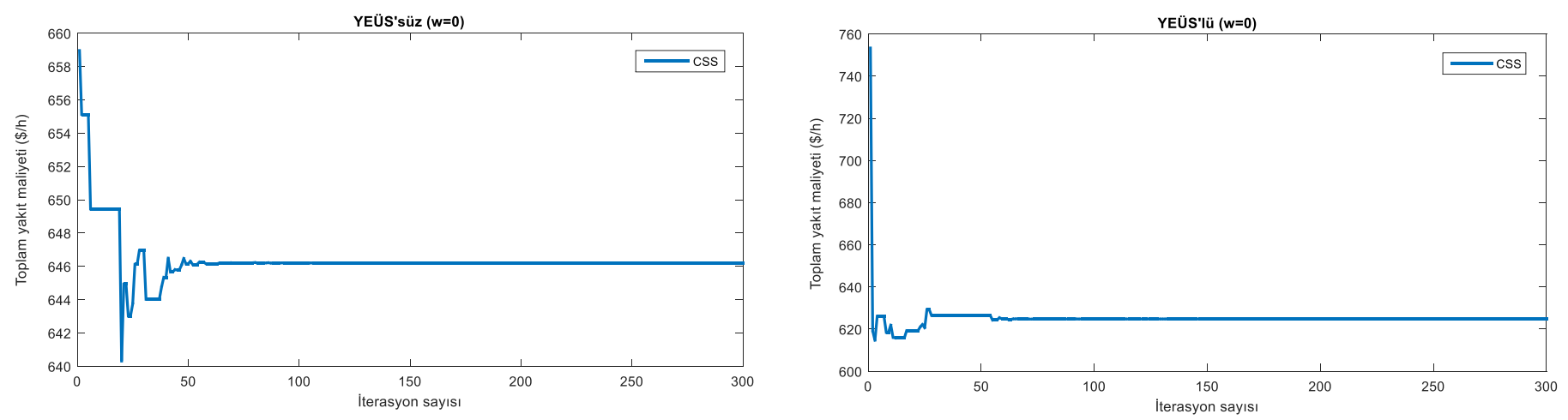

Şekil 8. İterasyon sayısına göre toplam yakıt maliyetlerindeki değişimler
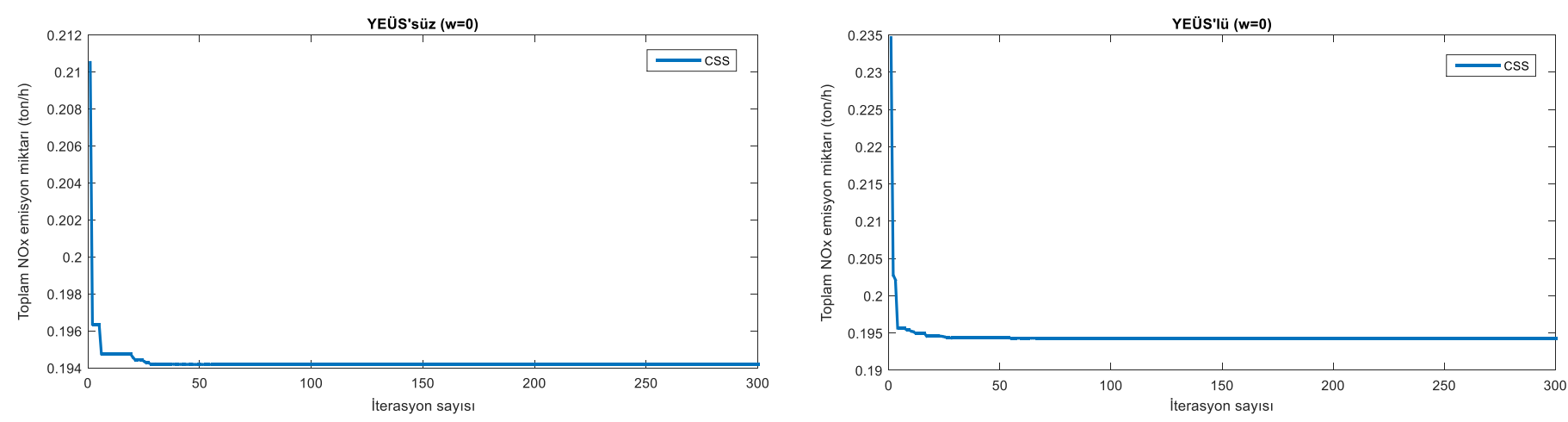

Şekil 9. İterasyon sayısına göre toplam $N O_{x}$ emisyon miktarlarındaki değişimler 

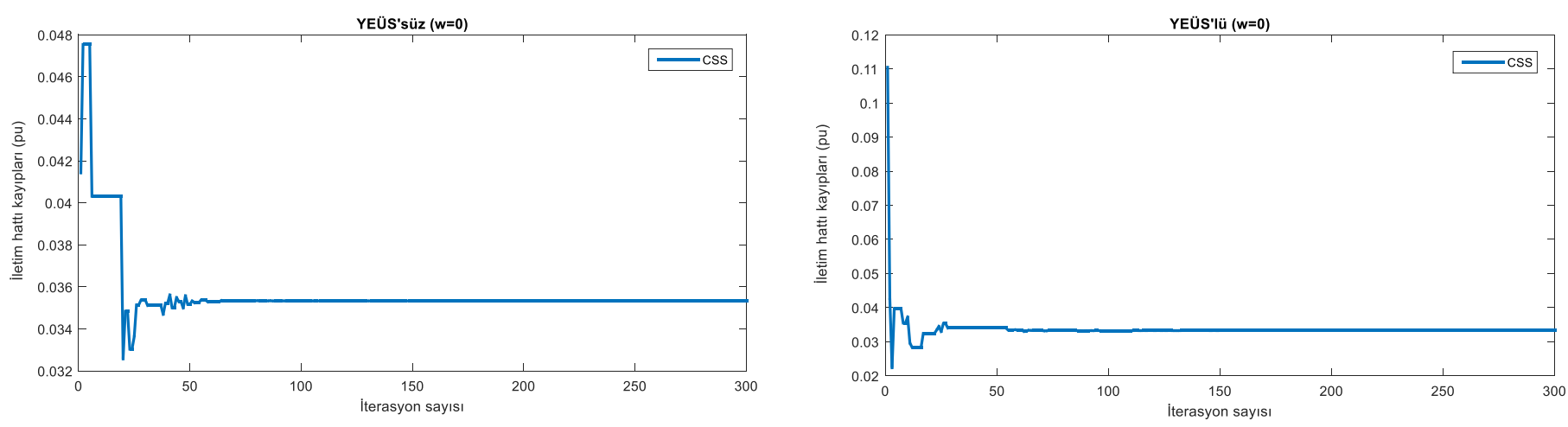

Şekil 10. İterasyon sayısına göre iletim hattı kayıplarındaki değişimler
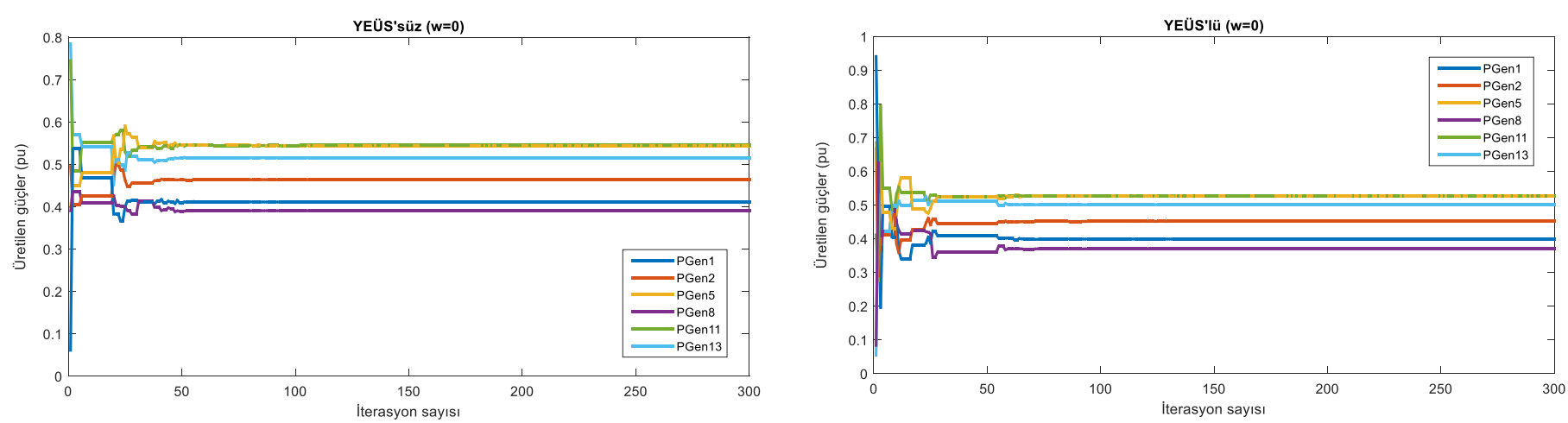

Şekil 11. İterasyon sayısına göre üretilen aktif güçlerdeki değişimler
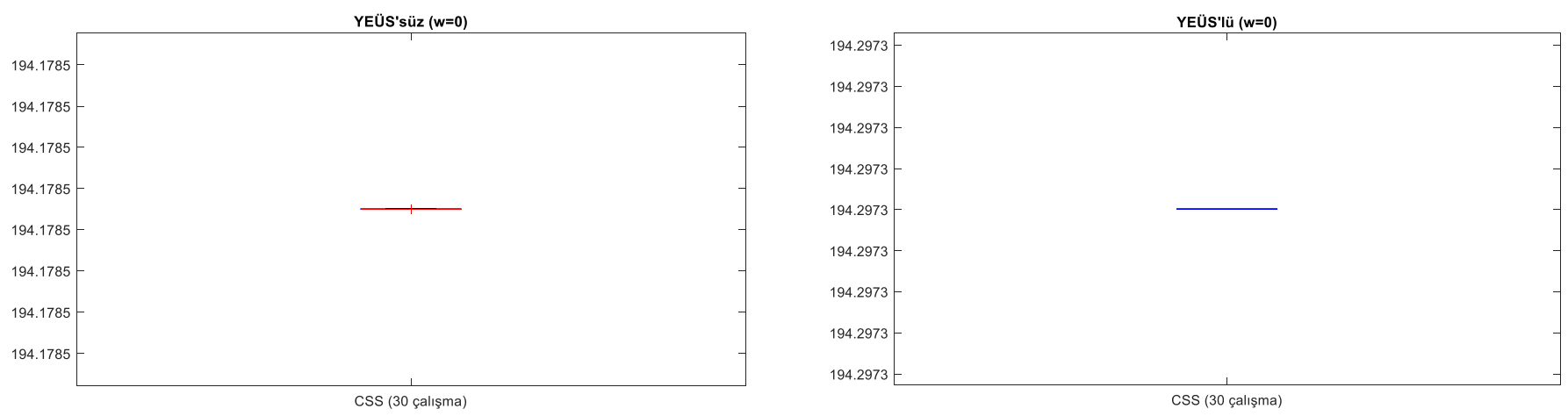

Şekil 12. 30'ar çözüme ait kutu grafikleri

$w=0,0$ için verilen grafiklerden Şekil 8 incelendiğinde yakıt maliyetindeki değişimlerin hem YEÜS'süz hem de YEÜS'lü durum için yaklaşık 60. iterasyonda en iyi değerlerine yakınsadığı görülmektedir. YEÜS'süz durumda toplam yakıt maliyeti değeri $w=0,0$ için $646,207000 \$ / h$, YEÜS'lü durumda ise $624,801621 \$ / h$ olarak elde edilmiştir. Bu durumda elde edilen ekonomik fayda yaklaşık $22 \$ / h$ 'dir. İletim hattı kayıplarına bakıldığında da iki sisteminde iletim hattı kayıpları yaklaşık aynıdır. Şekil 12 'de verilen kutu grafiklerine bakıldığında her iki durum için de kararlı bir arama yapıldığı görülmektedir.

\section{Sonuç}

Enerji üretim sistemlerinin doğru planlanması ve üretim sırasında çevreye salınan zararlı gazların azaltılması için çevresel/ekonomik güç dağıtımı problemlerinin çözümü, elektrik mühendisliğinde oldukça büyük bir öneme sahiptir. Çalışmada konveks yakıt maliyet fonksiyonlarına sahip bir güç sistemi için iki kez çevresel/ekonomik güç dağıtımı yapılmıştır. Parasal ve çevresel iki farklı amaç, ağırlıklı toplam metodu kullanılarak aynı amaç fonksiyonunda birleştirilmiştir. İlk durumda mevcut yükün tamamının termik üretim birimleri tarafından karşıllandığı kabul edilmiş, ikinci durumda ise belirlenen baralara bağlı yüklerin yenilenebilir enerji üretim sistemleri tarafından beslendiği varsayılmıştır. İki durum içinde aynı güç sistemi, farklı ağırlık değerleriyle CSS algoritması ile 30'ar kez çözülmüştür. Yapılan çözümlerde CSS algoritması birinci durumda $w=1,0$ için 605,998369 $\$ / h$ 'lik yakıt maliyeti değerine 6,97118 sn'de, $w=0,0$ için 0,194178 ton $/ h^{\prime}$ 'lik toplam $N O_{x}$ emisyon miktarı değerine 7,71113 sn'de yakınsamıştır. Bu durum için iletim hatlarında meydana gelen ve B-kayıp matrisleri ile hesaplanan kayıp aktif güç değeri $w=1,0$ için $0,025562 \mathrm{pu}$, $w=0,0$ için $0,035330 \mathrm{pu}$ olmuştur. Sisteme yenilenebilir enerji santrallerinin eklendiği durumda ise CSS algoritmas $w=1,0$ için $584,6239719 \$ / h$ 'lik yakıt maliyeti değerine 6,94812 sn'de, $w=0,0$ için 0,194297 ton/ $h$ 'lik toplam $N O_{x}$ emisyon miktarı değerine ise 
7,53539 sn'de yakınsamıştır. Bu durum için iletim hatlarında meydana gelen kayıp aktif güç değeri $w=1,0$ için $0,024417 p u, w=0,0$ için $0,033254 \mathrm{pu}$ olmuştur.

Çalışmanın yapılmasındaki amaç yenilenebilir enerji santrallerinin çevresel/ekonomik güç dağıtımı probleminde toplam yakıt maliyeti, toplam NOx emisyon miktarı ve iletim hattı kayıpları üzerine etkilerinin yaklaşık olarak hesaplanmasıdır. Daha sonra yapılacak çalışmalarda iletim hattı kayıplarının yük akışı ile daha doğru olarak hesaplanması, sisteme entegre edilecek yenilenebilir enerji santrallerinin şebekeye güç sağladığı varsayılarak etkilerin daha gerçekçi bir yaklaşımla belirlenmesi düşünülmektedir.

\section{Bilgilendirmeler}

Bu çalı̧̧ma Burdur Mehmet Akif Ersoy Üniversitesi destekleriyle Burdur'da düzenlenen 2. Uluslararası Teknoloji ve Bilim (Techno-Science 2019) sempozyumunda özet metin bildiri olarak sözlü sunulmuştur.

\section{Kaynakça}

Abarghooee, R.A., Niknam, T., Roosta, A., Malekpour, A.R., Zare, M., (2012). Probabilistic multiobjective wind-thermal economic emission dispatch based on point estimated method. Energy, 37(1), 322-335.

Basu, M., (2019). Multi-area dynamic economic emission dispatch of hydro-wind-thermal power system. Renewable Energy Focus, $28,11-35$.

Bhattacharya, A., Chattopadhyay, P.K., (2011). Solving economic emission load problems using hybrid differential evolution. Applied Soft Computing, 11, 2526-2537.

Dubey, H.M., Pandit, M., Roosta, A., Panigrahi, B.K., (2015). Hybrid flower pollination algorithm with time-varying fuzzy selection mechanism for integrated multi-objective dynamic economic dispatch. Renewable Energy, 83, 188-202.

Jadhav, H.T., Roy, R., (2013). Gbest guided artificial bee colony algorithm for environmental/economic dispatch considering wind power, Expert Systems with Applications, 40, 6385-6399.

Jevtic, M., Jovanovic, N., Radosavljevic, J., Klimenta, D., (2017). Moth swarm algorithm for solving combined economic and emission dispatch problem. Elektronika ir Elektrotechnika, 23(5), 21-28.

Jiang, S., Ji, Z., Wang, Y., (2015). A novel gravitational acceleration enhanced particle swarm optimization algorithm for wind-thermal economic emission dispatch problem considering wind power availability, International Journal of Electrical Power \& Energy Systems, 73, 1035-1050.

Kaveh, A., Talatahari, S., (2010). A novel heuristic optimization method: charged system search. Acta Mechanica, 213(3-4), 267-289.

Özyön, S., Temurtaş, H., Durmuş, B., Kuvat, G., (2012). Charged system search algorithm for emission constrained economic power dispatch problem. Energy, 46(1), 420-430.

Özyön, S., Yaşar, C., Temurtaş, H., (2015). Hibrit (Rüzgâr-Güneş) enerji sistemlerinin çevresel ekonomik güç dağıtımı üzerine etkilerinin incelenmesi. International Multidisciplinary Congree of Eurasia (IMCOFE'15), 1-5 September 2015, Üsküp, 364-377.

Tabrizian, Z., Amiri, G.G., Beigy, M.H.A., (2014). Charged system search algorithm utilized for structural damage detection. Shock and Vibration, 2014, 1-13.

Zhu, C., Wang, J., Qu, B., (2014). Multi-objective economic emission dispatch considering wind power using evolutionary algorithm based on decomposition. International Journal of Electrical Power \& Energy Systems, 63, 434-445. 